\title{
ETHNOMEDICINAL STUDIES FOR THE TREATMENT OF TYMPANITES AMONG CATTLE IN GWALIOR REGION OF MADHYA PRADESH
}

\author{
Sushmita Shrivastava*, Rajesh Singh Tomar \\ Amity Institute of Biotechnology, Amity University Madhya Pradesh, India \\ *rssush@gmail.com
}

\begin{abstract}
Ethnomedicines are the traditional medicines which are effectively being used for the treatment of humans as well as cattle since the ancient times. This means of treatment is quite beneficial, cheap and easily accessible to people below poverty line. Since, the knowledge of such medicines is restricted among few people, it needs to be popularized and systematized. Cattle being an important part of our society gets affected by various types of diseases. Tympanites is one of the common ailments among cattle in Gwalior region of M. P. The present study aims to collect the information regarding treatment of tympanites among cattle by the effective herbal medicines available in the region and also to document this for the benefit of society. The study involves keen survey of area and interviewing people to get information. Achyranthus aspera, Balanites aegyptiaca, Zingiber officinale, Citrus limona, Trachyspermum ammi are found to be valuable plants capable of effectively curing bloat in the cattle. By the study and frequent observations, it has been found that traditional medicines are very effective in the treatment of bloat among cattle.
\end{abstract}

KEYWORDS: Tympanites, cattle, treatment, ethnomedicines, diseases.

\section{INTRODUCTION}

Ethnomedicines are basically traditional medicines used by the rural or aboriginals of our society from the long period of time. These are highly effective, cheap and easily available recipes which are generally found in our vicinity. People have full faith over them. These medicines are found to be widely applied by rural people for curing themselves as well as their animals. The knowledge about these formulations and recipes are transferred from generations to generations by word of mouth. The knowledge of these traditional medicines is not only beneficial for the conservation of biodiversity but also aids in upliftment of community health ${ }^{1}$. They are better choice against modern synthetic medicines, because allopathic drugs enter into living system of livestock and the presence of these drugs in milk and meat produces toxicity in the consumers. Livestock or cattle are the very commonly domesticated animals by rural areas. They are responsible for economic growth of our country. Hence their health has kept utmost importance. A variety of ailments and diseases effect the health of domesticated cattle but the diseases related to alimentary canal and integument are most common. The owners of cattle, folk practioners, milkmen and farmers of our society treat diseased cattle with the help of local herbs and traditionally known plants.

A worth notable work in this field had already been done by various efficient 
workers in several region of India like Uttarakhand $^{2,3}$, West Bengal ${ }^{4}$, Jammu and Kashmir $^{5}$ and Southern India ${ }^{6}$. Even in abroad, many workers had tried to find out the hidden traditional knowledge of their country in several parts of world like Nigeria $^{7}$, Pakistan $^{8,9}$, Nepal $^{10}$ etc. But still much has to be carried out in this field.

In the present study an effort has been carried out to document knowledge of herbal medicines used by rural for treatment of tympanites among cattle. Tympanites or bloat is one of the common ailments of cows and buffaloes in Gwalior region of M.P. It is an ailment of alimentary canal in which cattle shows distended rumen (swollen abdomen). It is caused either by faulty or unusual feeding or by loss of tone of rumen muscles.

\section{MATERIALS \& METHODS}

The study was taken place in the Gwalior region of Madhya Pradesh, in which 16 dairy spots and 30 villages were selected for the investigations. The present study is based on keen observation and interaction with people of Gwalior region. For the study, specific villages and dairy spots were identified in Gwalior region and people were interviewed by a set questionnaire regarding the ailment, its causative agents, symptoms, types of plants used in treatment, dose and dosage, changes appeared in cattle during treatment and the recovery period.

\section{RESULTS AND DISCUSSION}

As Gwalior is tropical region so summers are quite longer and it had been found that tympanites is quite prevalent during summers when temperature varies from 29 to 46 degree Celsius. Followings are the formulations which were generally used by the villagers for the treatment of tympanites among cattle.

(1) Leaves of Achyranthes aspera (200 gm) are grinded and mixed with Brassica campestris oil $(200 \mathrm{ml})$ and given twice a day to the affected cattle.

(2) Ferula asafoetida (100 gm) and baking soda (50 gm) are mixed with jaggery (200 gm) to form balls. 1 ball is given twice a day for 2 days.

(3) Mixture of Cocos nucifera oil and turpentine oil (100 gm each) is given to the affected cattle twice a day for 2 days.

(4) Poori of wheat flour are fried in ghee/ vegetable oil and given to the affected cattle.

(5) Seeds of Cannabis sativa (20 seeds) are fried and mixed with jaggery (100 gm) and given once a day.

(6) Mixture of Ferula asafoetida (10 gm), dried Zingiber officinale (30 gm), Nicotiana tabacum (10 gm) and black salt (20 gm), is given with the chapatti once a day for 2 days.

(7) Decoction of dried Zingiber officinale (50 gm), Curcuma longa (50 gm) and jaggery (200 gm) in water (1.5 litre) 
called onti, is given.

(8) Seeds of Balanites aegyptiaca (20 gm) are grinded and mixed with water $(500$ $\mathrm{ml}$ ) and given with the help of Bamboo pipe (nay) twice a day.

(9) Leaves of Citrus limona and Acacia nilotica (100 gm each) are mixed with baking soda and given to the affected goat.

(10) Mixture of leaves of Citrus limona and Acacia nilotica are grinded and mixed with black salt and given twice a day for 3 days.

(11) Soil of termerium (bami) is mixed with sugar pabbles (batase) and fed.

(12) Dried Zingiber officinale (50 gm), black salt (50 gm), Capsicum annum (100 gm) and baking powder (50 gm) are grinded and mixed with jaggery (200 gm) and given twice a day.

(13) Grains of Sorghum bicolor (200 gm) are grinded and mixed with kerosene $(500 \mathrm{ml})$ and given once a day for 2 days.

(14) Fresh leaves of Ricinus communis (100 to $200 \mathrm{gm}$ ) are fed once a day to the affected cattle.

(15) Trachyspermum ammi (50 gm) and Curcuma longa powder (10 gm) are mixed in jaggery (200 gm) is given twice a day for 3 days.

(16) Fruit of Balanites aegyptiaca is grinded and mixed with jaggery and fed to the affected cattle.

(17) Sesamum indicum oil $(200 \mathrm{ml})$ is mixed with same amount of Kerosene is fed once a day for 3 days.

(18) Grinded leaves of Maytenus emarginata with chapatti are given to treat tympanites of the cattle.

(19) Ferula asafoetida (10 gm) is grinded and mixed in mustard oil (250 gm) and given to the affected cattle.

(20) Endosperm of Cocos nucifera (300 to $400 \mathrm{gm}$ ) is crushed with Allium sativum $(50 \mathrm{gm})$ and is fed to the affected cattle.

(21) Crushed bulbs of Urginea indica are mixed with jaggery (200 gm) and fed to the affected cattle for immediate relief.

(22) Battisa masala (A local blend) is mixed in hot water and given.

(23) Decoction of Trachyspermum (50 gm), dried Zingiber officinale (100 gm) and jaggery $(250 \mathrm{gm})$ are mixed in water $(500 \mathrm{ml})$ and given.

(24) Human urine (200 $\mathrm{ml}$ ) is also given to the affected cattle.

(25) Leaves of Ricinus communis coated with castor oil are fed to affected cattle.

(26) Decoction of seeds of Trigonella foenum- graecum seeds (200 gm) and jaggery $(500 \mathrm{gm})$ are boiled in water ( 2 litre) and given to the affected cattle.

By keen survey of literature, it had been observed that different workers mentioned variety of treatment recipes like Aegle marmelos ${ }^{10}$, Cassia fistula ${ }^{11}$, dried fruits of Capsicum annum ${ }^{12}$, paddy husk ${ }^{13}$, seeds of Carum copticum $^{14}$, leaves of 
Curcuma pseudomontana ${ }^{15}$, oil of Pinus halepensis ${ }^{16}$ and bark of Ficus glomerata ${ }^{17}$ to overcome bloat. However our findings were found to be different from other coworkers. Types of recipes used in treatment found to be differed according to locality and availability of plants.

\section{CONCLUSION}

Traditional medicines have their utmost importance in their own. They are highly effective, harmless, affordable and have no side effects. But this knowledge is very megre and required to be popularized for the welfare of society. As far as the diseases of cattle are concerned, these herbal recipes are better alternative against harmful allopathic drugs. Our villages and aboriginals have enormous knowledge of these medicines, but there is urgent need of their documentation and systematization. The present work was a little effort towards this direction. Still much has to be done for the popularization of these traditional medicines for the benefit of society.

\section{ACKNOWLEDGEMENT}

The study was carried out by the cooperation of all the villagers and dairy persons who had provided us valuable information regarding ethnomedicine.

\section{REFERENCES}

1. Verma, R.K., 2014. An ethnobotanical study of plants for the treatment of livestock diseases in Tikamgarh district of Madhya Pradesh. Asian Pac. J. Trop. Biomed., 4(1): S460S467.
2. Tiwari, L. \& P.C. Pande, 2010. Ethnoveterinary medicines in Indian perspective: Reference to Uttarakhand, Himalaya. Ind. J. Trad. Know., 9(3): 611-617.

3. Khadda, B.S., B. Singh, D.V. Singh, J.L. Singh, S.K. Singh \& C.B. Singh, 2018. Ethnoveterinary practices of goat farmers in tarai region of Uttarakhand. Ind. J. Smal. Rumin., 24(1): 146-149.

4. Saha, M.R., D.D. Sarker \& A. Sen, 2014. Ethnoveterinary practices among the tribal community of Malda district of West Bengal, India. Ind. J. Trad. Know., 13(2): 359-367.

5. Khateeb, A.M., S.A. Khandi, P. Kumar, M.S. Bhadwal \& R. Jeelani, 2015. Ethnoveterinary practices used for the treatment of animal diseases in Doda district, Jammu \& Kashmir. Ind. J. Trad. Know., 14(2), 306312.

6. Jayakumar, S., S. Sathiskumar, N. Baskaran, R. Arumugam \& V. Vanitha, 2017. Ethnoveterinary practices in Southern India for captive Asian elephant ailments. $J$ Ethnopharm., 200: 182-204.

7. Adedeji, O.S., T.O. Akande, A.O. Akinwumi, D.O. Okunlola \& M.D. Shittu, 2013. Ethnoveterinary practices among sheep rearers in Ona- Ara local Government of Oyo state Nigeria. Sokota J. Vet. Sci., 11(1): 3844 .

8. Farooq, Z., Z. Iqbal, S. Mustaq, G. Muhammad, M.Z. Iqbal \& M. Arshad, 2008. Ethnoveterinary practices for the treatment of parasitic diseases in Cholistan desert (Pakistan). J. Ethnopharm., 118(2): 213-219.

9. Dilshad, S.M., N.U. Rehman, Z. Iqbal, G. Muhammad, A. Iqbal \& N. Ahmad, 2008. An inventory of the ethnoveterinary practices for reproductive disorders in cattle and buffaloes, Sargodha district of Pakistan. J. Ethnopharm., 117(3): 393-402.

10. Mala, B. \& R.B. Chhetri, 2012, Ethnoveterinary practices of some plant species by ethnic people of Parbat district, Nepal. Kathmandu. Uni. J. Sci. Eng. Tech., 8(1): 44-50. 
11. Borthakur, S.K., K. Nath \& T.R. Sharma, 1998. Inquiry into old lead ethnoveterinary medicine for the treatment of elephant in Assam. Ethnobot., 10: 70-74.

12. Patil, S.H. and M.M. Merat, 2003. Ethnoveterinary practices in Satpudas of Nandurbar district of Maharashtra. Ethnobot., 15: $103-106$

13. Rao, M.L.S., Y.N.R. Varma \& R. Vijay Kumar, 2008. Ethnoveterinary medicinal plants of catchment area of river Papagni in the Chittoor and Ananthapur district of Andhra Pradesh. Ethnobot. Leaf., 2: 217-226.

14. Majhi, S.K. 2008. Indigenous technical knowledge for control of insect pest and livestock disorders. Ind. J. Trad. Know., 3: 463-465.
15. Sehgal, A.B. and S.K. Sood, 2013. Ethnoveterinary practices for herbal cure of livestock used by rural populace of Hamirpur, (H.P.), India. IOSR J. Agri. Vet. Sci., 3(1): 714.

16. Patil, U.S. and O.S. Deshmukh, 2015. Plants used in ethno-vetrinary medicines by tribal people in Betul district, Madhya Pradesh, India. J. Glob. Sci., 4(8): 3049-3054.

17. Khandelwal, N. 2017. Ethnoveterinary practices among women of Banaskantha district, Gujarat. Ind. J. Trad. Know., 16(4): 614-625.

18. Kaur, D., K. Jaiswal \& S. Mishra, 2015. Ethnoveterinary practices in India: A Review. Euro. J. Pharm. Med. Res., 2(7): 139-143. 